\title{
Notas Sobre Muerte Sin Fin
}

Sin duda alguna, Muerte sin fin de José Gorostiza es uno de los mayores logros de la poesía contemporánea. Igualmente indiscutible sería afirmar que constituye uno de los poemas más difíciles de captar en toda su irisada trayectoria. El cuerpo de crítica es extremadamente reducido, abarcando varias reseñas y unos cuantos ensayos, entre los cuales son de especial interés los de Octavio Paz, Raúl Leiva y Ramón Xirau. ${ }^{1}$ Que sepamos, no existe un análisis sistemático del poema, ni estudio que subraye la estructura básica y la relación cuidadosamente trabada de las distintas partes. Tal es el propósito de este ensayo.

Poco ha publicado José Gorostiza: Canciones para cantar en las barcas (1925), cuatro sonetos aparecidos en Letras de México en I939, "Preludio", publicado en Universidad, y Muerte sin fin, de 1939. Tal escasez sospechamos que se deba al complicado proceso creador de Gorostiza. Muerte sin fin es de una densidad y una complejidad tales que habrá costado una extraordinaria concentración y un largo período de gestación; la dificultad no estriba en la oscuridad sino en el hecho de que funciona el poema sobre una multiplicidad de niveles. Puede que sea la última obra de Gorostiza; en todo caso, representa la culminación de una tendencia cada vez más importante en su obra hasta que se convierte en la tónica. Es dudoso que pudiera superarse; cualquier nueva obra que publique creemos que se dirigirá por nuevos caminos.

I Octavio Paz, "Muerte sin fin", en Las peras del olmo, México, Imp. Universitaria, 1957, p. 105-114; Raúl Leiva, "José Gorostiza", en Imagen de la poesía mexicana contemporánea, México, Imp. Universitaria, 1959, 109-122; Ramón Xirau, "Descarnada lección de poesía", en Tres escritores de la soledad, México, Antigua Librería Robredo, 1955, p. 13-20. 


\section{LUS ANTECEDENTES}

Canciones es notable por la maestría en el ejercicio del haikai tan en boga allá por la tercera década de este siglo, y por el empleo de formas tradicionales que cantan al estilo de la poesía popular de los siglos XVI y XVIr. Antecedente claro del tema de Muerte sin fin es un frag. mento del poema "La orilla del mar". Se trata de los versos "No es agua ni arena / la orilla del mar," prefiguración del conflicto entre forma y materia. Apenas esbozado aquí, llega este tema a ser la nota caracte. rística de los cuatro sonetos. Estos son difíciles porque comienzan en plena materia, sin proporcionatnos puntos externos a los cuales asirnos. El primero y más difícil parece que se trata del momento de creación artística. En el momento de creación, el poeta se ve acaparado por "... una muerte de agujas ... que le estrangula." (Dicho sea de paso, esta misma metáfora se emplea en Muente sin fin para señalar el conflicto entre forma y materia.) Es el tema la tentativa de armonizar la pala. bra y el significado, de plasmar la materia poética.

En el soneto segundo dice Gorostiza que la forma es permanente, que se contiene a sí misma. Empleando la metáfora del agua que se hace clave de Muerte sin fin, declara que "Te contienes - oh Forma- en el suntuoso/muro que opones de encarnada espuma..." La forma del agua es eterna a pesar del fluir del agua contenida; es un reposo dinámico, cambiante pero permanente. Los últimos versos trasladan este tema a la creación artística. La forma es igual, no obstante la fuente de la cual provenga; permanece preexistente y predeterminada, siempre igual.

En el soneto tercero, se persigue este tema a través del encuentro de la materia y la forma, refiriéndose ya no solamente al agua sino a toda la existencia. Como señaló Ramón Xirau², aquí el agua llega a ser muy a las claras metáfora del flujo, del cambio incesante que caracteriza al universo. La forma, pues, no es "tierno simulacro", no es apariencia de superficie, sino el momento fijo en el cual la materia da con la expresión que le hace falta, la expresión sin la cual permanece masa informe. Este momento fijo es la plenitud de la existencia y a la vez su muerte, ya que no puede repetirse. En el soneto final, se repite esta desgarradora afirmación: "Tu destrucción se gesta en la codicia/de esta sed ..."

\footnotetext{
2 Tres poetas de la soledad, 14.
} 
Las dificultades presentadas por los sonetos se mitigan en "Preludio", un poema de setenta y tres versos que ataca el problema de una manera más inteligible. De hecho, es un preludio a Muerte sin fin. El poeta se dirige a la forma pura, a la palabra desnuda de significado, a los signos vacíos:

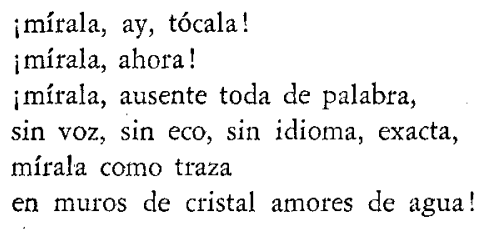

Este fijarse en la pura forma y en el arcoiris de significados con los cuales se le puede cargar, y el conflicto entre la contemplación asombrada de los materiales del poema y la lucha por crear de ellos el poema, está en las raices de Mukirte sin fin. En su discurso de entrada a la Academia Mexicana de la Lengua, dijo Gorostiza que la poesía es "... una especulación, un juego de espejos, en el que las palabras, puestas unas frente a otras, se reflejan unas en otras hasta lo infinito y se recomponen en un mundo de puras imágenes donde el poeta se adueña de los poderes escondidos del hombre y establece contacto con aquél o aquéllo que está más allá."’3 Clarifica esto el concepto que tiene Gorostiza de una forma preexistente que hay que modificar para que le cuadre a una materia independiente y recalcitrante: el significado. $\mathrm{Ha}$ dicho Torres Bodet que la técnica de Gorostiza es laminatoria, o sea que lamina la obra creada con una serie de capas de significación hasta dar con la obra cabal.4 "Preludio" demuestra tanto el gozo del artista en esta maleabilidad de la forma "... se remonta insensata una palmera / para estallar en su ficción de cielo, / maestra en fuegos no, / mas en puros deleites de artificios ..."-como su quedarse atónico ante el milagro físico de la voz, vale decir, de la comunicación:
¿No aqui su angustia asume 1a inocencia de una hueca retórica de lianas?
Aquí, entre líquenes de orfebrería que arrancan de minúsculos canales, ¿no echó a tañer al aire sus cándidas mariposas de escarcha?

3 "Notas sobre poesía", Estuciones, III, 9 (Primavera, 1958), p. 3.

4 Tiempo de arenct, México, Fondo de Cultura Económica, 1955, p. 81. 


\section{MUERTE SIN FIN}

La indiscutible dificultad de la obra maestra de Gorostiza radica precisamente en esta admiración por la palabra - la forma-y por los múltiples significados - la materia - con los cuales se le puede cargar. Funciona el poema en una serie de niveles de un modo simultáneo, todos los cuales presentan uno u otro aspecto de la general relación de forma y materia, relación que llega a veces a ser antinomia. Aparece esta rela. ción bajo una serie de disfraces: el vaso y el agua, la palabra y el significado, y-variantes de la relación primaria - comunicación y esterilidad. Dios y el azar, vida y muerte. A veces varios niveles están en vigencia; otras veces se refiere el poeta a un nivel sobretodo. Se dificulta aún más la comprensión del poema a causa de la mueca sardónica que se asoma a ratos detrás de la máscara contorsionada. El producto total es una meditación enormemente compleja sobre la totalidad de la existencia.

Está dividido el poema en diez partes, varias de las cuales se subdividen a su vez. Sin embargo, no se amontonan al azar, sino que obedecen a una rigurosa estructuración intelectual. Repetidamente ha expre. sado Gorostiza su desprecio por el concepto moderno de la lírica y su adhesión a una idea más antigua de lo que es:

Dentro de la lírica, cuando menos como la concebimos en la actualidad, parece que la única causa capaz de desatar un poema es el dato autobiográfico. La conmoción que un acontecimiento produce en el poeta al incidir sobre su vida personal, se traduce, convertida en imágenes, en una emanación o efluvio poético; pero no en un poema, porque esta palabra 'poema', implica organización inteligente de la materia poética. Treinta o cuarenta composiciones (en las cuales se puede reconocer siempre el contenido de pura, auténtica poesia) suelen formar, unas tras otras, lo que el público llama 'un libro de versos'. (¿Qué horrible expresión: un libro de versos!) $Y$ en el libro podrá haber cierta uniformidad de emoción y de estilo, y de un poema a otro, tales o cuales eslabones que dan la sensación de una continuidad invisible; pero el libro no mostrará, a su vez, la unidad de construcción que nos agrada encontrar en un libro. La suma de treinta momentos musicales no hará nunca el total de una sinfonía.5

Las dos divisiones del poema consisten cada una en cuatro secciones que desarrollan el tema; a la cuarta y la novena les siguen sendas líricas. Estas líricas no se parecen a las cuatro secciones anteriores, sirviendo así

5 "Notas sobre poesía", p. 9. 
para romper la tensión. Hay versos que se repiten total o parcialmente, atando las secciones; hay varias subsecciones que persiguen distintos aspectos de un mismo tema. En suma, Mworte sin fin, si su contenido refleja un universo caótico cuya única realidad es la muerte, es en sí un monumento rigurosamente estructurado a la organización intelectual de este caos.

\section{I. "LleNo dE Mí..."}

Como queda dicho ya, el tema básico del poema es la dialéctica de forma y materia, presentada al comienzo como conflicto, para luego representarse de distintos modos a través del progresivo desarrollo hasta que por fin llega el poeta al concepto de la fusión de los dos contrarios y la consiguiente destrucción de la unidad: la muerte. Como lo encontramos primero, el conflicto está expresado en términos del enigma solipsista. "Lleno de mí, sitiado en mi epidermis ..." Aislado por sus propios límites, contenido por una forma de la cual no puede evadirse, el hombre está suspendido en una especie de desamparo, incapaz de escaparse de la forma: "...un dios inasible que me ahoga..." Encuentra un símbolo de su propio ser al mirar el vaso de agua, ya que el agua, por sí sola, carece de forma. Pero cuando se vierte el agua en el vaso, cobra forma, impuesta desde fuera por un agente que le es desconocido. De igual manera el poeta es informe en el sentido físico sin la superficie corporal que, mientras le da forma, le aisla del mundo exterior. Y, según Gonostiza, también es informe el hombre en el nivel de la conciencia, sin el poder organizador del intelecto que es la forma de la conciencia humana. $\mathrm{Y}$ ésta también ha sido conferida por un agente desconocido, un dios intangible e imperceptible. Pero el agua dentro del vaso "... cumple una edad amarga de silencios / y un reposo gentil de muerte niña, / sonriente, que desflora / un más allá de pájaros en desbandada." Es decir, como el agua pierde forma al verterse fuera del vaso, así la pierde también el hombre al renunciar a la inteligencia: muerte espiritual.

En el tercer verso de esta parte surge una pregunta relativa a la existencia de este agente desconocido. Si es intangible, puede que sea también inexistente. Pero es el vaso "... un ojo proyectil que cobra alturas / y una ventana a gritos luminosos / sobre esa libertad enardecida / que se agobia de cándidas prisiones!" El vaso, vale decir, la forma, es un ojo que todo lo ve, una ventana hacia el significado. Ya que la omnividencia es calidad de Dios, es posible que sea éste la forma, o sea la 
inteligencia. Si Dios es la Forma, es intangible, invisible, pero sin embargo, existe.

\section{2. "MÁs Que VASO..."}

En la segunda parte se fija el poeta en lo que haya fuera de los límites arriba mencionados. Acaso este vacío que nos rodea, más allá de los límites físicos, Dios o comoquiera lo llamemos, sea toda forma. La percibimos, pero a través de una transparencia acumulada - el vaso, el aire- que tiñe de azul nuestro concepto de ella, tal como el agua tiñe el vaso y el aire al cielo. En este momento el poeta nos dice que esta forma "... nos estrecha / en islas de monólogos sin eco..." En otras palabras, la misma forma nos restringe, impide nuestra comunicación con la materia. Aquí se refiere a las dificultades de la comunicación poética y la muerte inevitable de esta comunicación. Ha dicho esto Gorostiza en sus "Notas sobre poesía":

Porque la poesía-no la increada, no, la que ya se contaminó de vida-ha de morir también. La matan los instrumentos mismos que le dieron forma: la palabra, el gusto, el estilo, la escuela. Nada envejece tan pronto salvo una flor, como puede envejecer una poesía. El poeta la hará durar un día más o un día menos, según su habilidad para sustraerla a la acción del tiempo. Su destino está trazado, a pesar de todo e irá a dispersarse en el fondo de la sabiduría popular... o bien, relegada a los anaqueles de las bibliotecas como un objeto arqueológico, quedará allí para curiosidad de los estudiosos y la inspiración de otros pectas. ${ }^{6}$

Pero Gorostiza apenas sugiere este concepto, para volver inmediatamente a la idea de Dios como forma que percibimos en las manifestaciones físicas que nos rodean. La identificación de los dos aspectos de la materia, agua y hombre, se desarrolla mediante una alusión a una metáfora empleada en la primera sección del poema: el agua en el vaso es como ojo omnividente que se yergue. Ahora el poeta desarrolla la leve identificación de Dios con forma. La sugerencia es que la forma, al conferir al agua esta coherencia, se puede identificar con Dios, o, por lo menos, con la lucha por comprender a Dios. Luego, habla el poeta del "... ojo de agua..." del cuerpo humano; del ". . río hostil de su conciencia..." que es "... jagua fofa, mordiente, que se tira, / ay, incapaz de cohesión al suelo!" Pero, poseída de forma, esta masa se redondea

6 "Muerte sin fin", p. 109. 
como el agua dentro del vaso, y se yergue: alusión clara al Darwinismo, fortaleciendo la creencia de que la forma de la conciencia es el intelecto, ya que sólo con la evolución del intelecto los animales empezaron a ponerse de pie, mientras se efectuaba el proceso evolucionario.

Pero no está satisfecho el poeta; tiene que agotar todas las posibilidades. Si rechazamos la inteligencia como forma de la vida, dice Gorostiza, quedamos con la posibilidad de que sea el tiempo, la esencia del hombre y origen de la vida. Pero si el tiempo es la esencia de la vida y el vaso es la forma del agua, ¿no es el vaso tiempo encarnado? ¿no es la existencia temporal del agua como entidad significativa?

¿También-mejor que un lecho-para el agua no es un vaso el minuto incandescente de su maduración?

Luego, la forma del hombre es el tiempo del vaso, el tiempo del intelecto, esta ". . febril diafanidad tirante..." Pero dentro de esta inteligen. cia, no pasa nada; nuestra misma forma impide que veamos a Dios, porque sólo percibimos lo que queda más allá de él. $\mathrm{Y}$ volvemos al vaso transparente; volvemos a la duda, porque si no podemos percibir la forma sino lo que yace más allá de ella, acaso esta forma en su aspecto divino, no exista. Quizá exista la forma nada más como forma, sin significado alguno, y el hombre esté condenido a existencia sin contenido.

\section{3. "Pero en las zonas ínfimas..."}

Esta tercera sección desarrolla el pensamiento final de la segunda: la imposibilidad de ver a Dios. El punto de partida lo son los versos que aparecen catorce versos antes del fin de la parte segunda; se desarrollan de un modo paralelo, enlazando las dos secciones y evitando un sen. timiento de ruptura.

\footnotetext{
Pero en las zonas infimas del ojo, no ocurre nada, no, sólo esta luz...
}

Los sigue un inesperado comentario sardónico al panteísmo franciscano. Como ha señalado Octavio Paz en su excelente ensayo sobre Mrerte sin fin, hay varios pasajes en los cuales se burla Gorostiza de los lectores, de la crítica y hasta de la poesía. Estamos seguros de que el poeta no habla. ba en serio al mentar ". . esta alegria, / única, riente claridad del alma." 
Mientras se desarrolla este tema, queda notorio el sarcasmo: el poeta de Muerte sin fin no va a estar hablando en serio de "Un disfrutar en corro de presencias, / de todos los pronombres..." "como única, riente claridad del alma". Destruye toda duda relativa a su propósito en los siguientes versos:

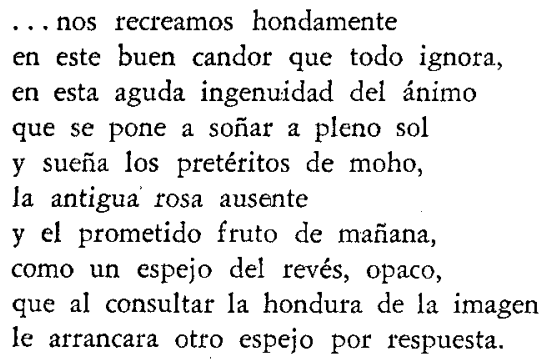

Esta contemplación proporciona una contestación a la pregunta fundamental, pero la contestación no es fundamental; nada más se cambia un espejo por otro. Organiza el mundo, pero de un modo artificial. La alegría inocente de San Francisco, las compensaciones de la fe, se repudian sardónicamente. $\mathrm{Ni}$ recibe mayor miramiento la interpretación mecanicista del universo:

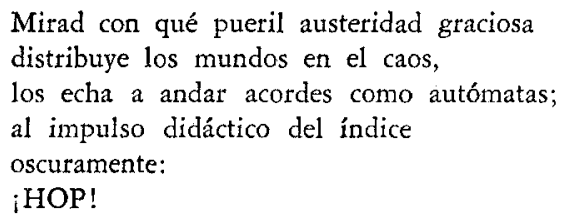

El mundo está organizado tan armoniosa y artificiosamente como una muñeca mecánica; acontecimiento al azar - "cintas de sorpresas"- se articulan engañosamente en un "... juego sinfónico. .." Vale decir, la interpretación mecanicista queda relegada al olvido porque no acarrea más contestación que la religiosa. Hasta el ritmo cíclico, base de la vida - "iplanta-semilla.planta!"- - es inútil. Termina la primera parte de esta sección en un canto sardónico a la vida, canto que empieza con parodia del vocabulario de la poesía paisajista para terminar en una cohetería de imágenes brillantes.

La segunda parte de esta sección reitera la técnica empleada por Gorostiza habitualmente para estructurar el poema: la repetición de un verso 
antes empleado. Corresponde esta técnica en la estructura al proceso dialéctico intelectual del poeta.

Mas en la médula de esta alegría, no ocurre nada, no;

sólo un cándido sueño...

Después de haber rechazado el "crescendo insostenible" representado en la parte anterior, aquí sugiere Gorostiza que acaso sea la existencia nada más un sueño, que siga con mirada fija el rumbo que se construye para sí mismo. Pero sería, este sueño producto de la inteligencia, y permanecemos atrapados por la pregunta perpetua. Peor, el sueño es corrompido, cruel, y voluntariamente se transforma en pesadilla; termina este rechazo del idealismo filosófico al estilo Berkeley en una serie de imágenes violentas del horror de la existencia:

Pero aún más - porque en su cielo impío nada es tan cruel como este puro goce somete sus imágenes al fuego de especiosas torturas que imagina

- las infla de pasión, en el prisma del llanto las deshace, las ciega con el lustre de un barniz, las satura de odios purulentos, rencores zánganos como una mala costra, angustias secas como la sed del yeso.

Pero aún más - porque, inmune a la mácula, tan perfecta crueldad no cede a límites perfora la substancia de su gozo con rudos alfileres;

piensa el tumor, la úlcera y el chancro que habrán de festonar la tez pulida, toma en su mano etérea a la criatura y la enjuta, la hincha o la demacra, como a un copo de cera sudorosa, y en un ilustre hallazgo de ironía la estrecha enternecido con los brazos glaciales de la fiebre.

Empieza la tercera parte de esta sección negando una vez más el sueño, y otra vez la negación se basa en la frase, "Mas nada ocurre". El lenguaje de este comienzo es llano, en contraste deliberado con las imágenes brutales de los últimos versos de la parte anterior. El sueño reconoce 
su fin inminente, su propia frustración, y se prepara. Es víctima -el sueño- del ritmo impuesto por él mismo, la incesante pauta externa, hasta que se muere (el sueño) asesinado por su propia mano. Los acontecimientos no relacionados - "cintas de sorpresas"- se convierten en "... cintas de cintas de sorpresas / que en un constante perecer enérgico, / en un morir absorto, / arrasan sin cesar su bella fábrica..." La articulación es fatal y el sueño tiene que perecer. Pero la cadena cíclica se repite infinitamente, cadena infinita de repetidos dramas de fatiga y muerte, "... muerte sin fin de una obstinada muerte..." Y la muerte llega a ser lo único perenne en un sueño que no es sino construcción impuesta por la inteligencia, "... soledad en llamas...., debatiéndose en busca de algún significado.

4. "¡OH, INTELIGENCIA, SOLEDAd EN Llamas ..."

Aparece este verso clave como definición del dilema humano en la sección anterior; ahora, en la cuarta sección, plantea definitivamente el callejón sin salida dentro del cual se retuerce la inteligencia, capaz de concebir pero sin peder crear. Puede fingir la vida, construyendo significados, pero jamás podrá otorgarles verdadera substancia. $Y$ si esto es cierto del hombre en su búsqueda de significados, es cierto también de su búsqueda de la expresión, la cual, como ha dicho Gorostiza en las "Notas sobre poesía", es por naturaleza una ocupación estéril. La inteligencia es incapaz de lo que no sea estéril contemplación solipsista, jncapaz de resolver el dilema "... de esa discordia/ que nutren vida y muerte inconciliables..." La dialéctica de materia y forma ha conducido a la dialéctica sin resolución de vida y muerte. Termina la cuarta sección en una aleluya amarga, dedicada a la inteligencia estéril, la cual es, en otro nivel, la forma impuesta desde afuera, y en otto, un Dios que acaso ni exista.

\section{5. "TZA LA FLOR SU ENSEÑA..."}

Como hemos visto las cuarto primeras secciones son una indagación en el problema del significado de la existencia; conduce dicha indagación al rechazo de toda explicación, rechazo que encuentra expresión en la irónica aleluya que remata la sección cuarta. La sigue la quinta como deliberada ruptura de tensión. En lo formal, es una serie de seguidillas, con estribillo después de cada tres seguidillas; contrastan estas formas tradicionales con el verso libre de las secciones anteriores. Por añadidura, 
después de la condensación de secciones, una hasta cuatro, suena la quinta a lírica popular. Pero que el lector no se despiste; esta quinta sección es tan estructurada como las otras. Las imágenes son sensuales: color, sabor, olor. La sección entera es casi exclusivamente nominativa: en sus cuarentas y seis versos hay seis adjetivos, sin contar unas cuantas expresiones adjetivales construidas a base de preposición más sustantivo, mientras que hay cincuenta y un sustantivos, inclusive los que aparecen en expresiones adjetivales. Los verbos, casi sin excepción, son de los más cotidianos: tiene, sabe, está, anda. El resultado total es una fiesta de sensación, de imágenes directas y concretas en contraposición a las especulaciones metafísicas de las secciones anteriores.

Esta sección está ligada a las anteriores mediante el estribillo tepetido con ligeras variaciones. Así, las tres primeras seguidillas tratan el olor de las flores - pero les sigue "Ay, pero el agua, / ay, si no huele a nada". El segundo grupo de seguidillas está cargado de colores: ámbar, azul, rojo, esmeralda, oro. Pero:

Ay, pero el agua,

ay, si no luce a nada.

$Y$ las seguidillas finales despliegan sabor, seguidas de "Ay, pero el agua, / ay, si no sabe a nada." El "baile" final comunica la desesperación del poeta después de su viaje --valga la reminiscencia de Dante- pero viaje cada vez más desesperado:

Pobrecilla del agua, ay, que no tiene nada, ay, amor, que se ahoga, ay, en un vaso de agua.

6. "EN FL RIgOR del VAso..."

Ha afirmado Octavio Paz que la primera mitad de Muerte sin fin representa la creación y muerte de Dios, y que la segunda es la creación y muerte del hombre. ${ }^{7}$ Podría decirse también que la primera mitad examina posibles explicaciones de la existencia, mientras que la segunda persigue hasta su despiadado desenlace el laberinto de la nada.

Empieza esta sexta sección de una manera llana en contraste con los versos de sabor popular de la quinta. Se persigue el tema del ansia de 
forma experimentada por el agua. O sea, la necesidad de la materia de tener inteligencia. Pero no basta la inteligencia nada más; hace falta la conciencia, "... un ojo, / para mirar el ojo que la mira..." Sólo a través de esta conciencia puede existir la materia:

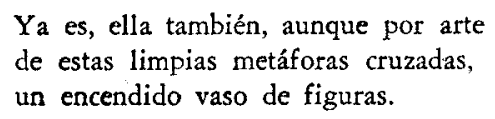

El agua ("ella") recibe pleno significado sólo cuando queda unida con la forma del vaso, aunque sea sólo por arte del rutilante prisma metafórico de la luz vista a través del vaso. También es cierto de la vida: sólo la fusión de materia e inteligencia en el momento de plena conciencia confiere significado, aun cuando sea "for arte", y aunque la unión sea transitoria. En otro nivel, aluden estos versos a la poesía: sólo a través de la casi milagrosa unificación de materia poética con significados, expresada esta serie de unidades en alianzas cambiantes mediante la me. táfora, puede cobrar significado la poesía. $\mathrm{Y}$ hemos visto ya que para Gorostiza la poesía es entidad singularmente efímera.

\section{7. "Pero el vaso en sí mismo no se cumple."}

Señala esta sección el comienzo del examen de la forma, examen que nos ha de conducir por el laberinto angustiado de las dos secciones siguientes. Contemplando el vaso vacío, el poeta lo califica de imagen de una decepción siniestra, ocultando en su rigor deshabitado nada más una triste claridad a ciegas. El "algo" que no puede definirse que reside dentro del vaso - "acaso un alma"- ansía cumplirse, porque sólo así se fundirá el contorno agudo con el contenido.

\section{8. "MAS LA Forma en sí Misma no se Cumple."}

Reiterando con alteraciones leves el primer verso de la sección anterior, emprende Gorostiza el examen que le conducirá tortuosamente al vacío consuelo final. Se divide esta octava sección en dos partes que reflejan el problema y la resolución que, en rigor, no es tal. Del verso segundo hasta el décimo son pura construcción formal, sonora edificio parnasista: la importancia de la forma tal como la ve la misma forma: 
Desde su insigne trono faraónico, magnánima,

deífica,

constelada de epítetos esdrújulos, rige con hosca mano de diamante.

Está orgullosa de su orondo imperio.

¿En las augustas pituitarias de ónice

no juega, acaso, el encendido aroma

con que arde a sus pies la poesía?

Este narcisismo formalista se aniquila súbitamente en los dos versos que le siguen:

¡Ilusión, nada más, gentil narcótico

que puebla de fantasmas los sentidos!

La forma a solas es "... jardín de huellas fósiles, / estruendoso fanal". Se halla sometida al tiempo, que aquí vuelve al poema; la forma es enorme armazón vacío que de repente se derrumba "... al soplo infantil de un parpadeo." En la segunda parte de esta sección encontramos una ligera nota de esperanza: aun en el colapso destinado de la forma, no puede negarse el sueño de la unión de forma y materia. La forma necesita a la materia, como a la materia le hace falta la forma; cada cual es inútil sin la otra. "El vaso de agua es el momento justo". Sí, después, este momento muere, siquiera ha existido una vez.

\section{9. "EN LA RED de CRISTAL ..."}

Estamos ya en el meollo del poema, la sección más larga a la vez que resumen de las conclusiones a las cuales ha llegado el poeta. Se divide esta sección en siete partes, que avanzan desde el concepto del momento único, al cual acabamos de llegar, hasta la desesperación total que sigue a la destrucción de dicho momento. Empieza la primera parte con el resumen aludido:

En la red de cristal que la estrangula,

el agua toma forma,

la bebe, sí, en el módulo del vaso, para que éste también se transfigure con el temblor del agua estrangulada que sigue alli, sin voz, marcando el pulso glacial de la corriente. 
Pero el vaso

- a su vez -

cede a la informe condición del agua...

Participa el agua en la forma, pero en este mismo instante la forma participa en el agua, de modo que la misma forma "... se pueda sustraer al vaso de agua..." Es el momento climático, el momento de fusión de forma y materia, el momento de la vida, de significado, conciencia, poesía.

Pero es solamente un instante, posible únicamente en el eterno instante mínimo cuando la forma pura se mezcla con la materia informe. En el nivel de la vida humana, es el momento de percepción cabal, cuando el hombre se da cuenta de que la vida es sólo un momento del ciclo perpetuo, "muerte sin fin de una obstinada muerte". Si es el momento del triunfo, es también la derrota irrevocable, ya que es el momento en que la forma se halla enlazada por la materia, el "... sopor primero..."

Las estrellas entonces ennegrecen.

Han vuelto el dardo insomne

a la noche perfecta de su aljaba.

La forma ha cumplido con su destino.

Es la segunda parte de esta sección un llanto por el mundo perdido, simbclizado éste por la canción de la belleza. En el momento en el cual la forma se hace temporal, sujeta a la muette, ahí se pierde el hombre, y con él, todo lo que ha creado. Es la negación de la inmortalidad, de la belleza, de la poesía. Lo que queda de esta novena sección desarrolla implacable pero desesperadamente las consecuencias de esta negación. En el momento de la terrible percepción, el hombre se da cuenta de la inutilidad de la lengua, ya que toda vida y toda creación están sujetas a la terrible ley del tiempo, la marcha hacia atrás de la evolución al revés. Después del momento de verdad, no queda sino la vuelta ". . a sus origenes / y al origen fatal de sus orígenes, / hasta que su eco mismo se reinstala/en el primer silencio tenebroso". Habla el poeta de la increíble, fatal vuelta al caos, atrapados como estamos en el frenesí de la muerte que es la única verdad, la verdad que nadie se atreve a aceptar. Debajo de la superficic, todo es materia infcrme, ahogada en el agua de su propio ser. En una revelación fina!, 
No hay ojo que nos vea, no hay mirada con la cual contemplar nuestra circunstancia. Hombre y Dios se hallan en el dominio de la terrible realidad de la muerte. Cuando la forma pura -inteligencia, significa. do- se entrega a la contemplación de su propia muerte, nada es posible, y la vida regresa a un mundo informe

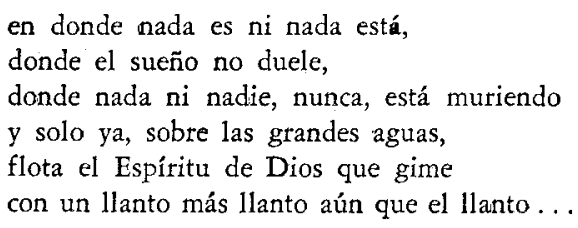

Y el poeta se mofa de la meta a la cual le ha conducido su terrible búsqueda, coreando el final sardónico de la primera mitad del poema mientras se burla de las aun más desesperantes conclusiones de la segunda:

\section{¡Aleluya, aleluya!}

Pero el hombre no resiste tanto. No pudiendo encararse con esta realidad, el poeta se refugia detrás de una mueca burlona:

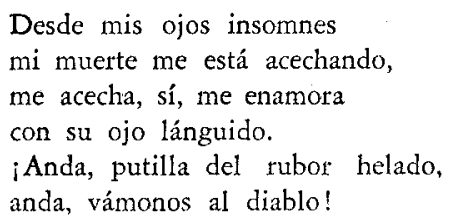

\section{CONCLUSIón}

No es nuestro propósito aquí el análisis estilístico, sino más bien hemos intentado trazar la línea temática. Tal análisis sería de gran provecho: un estudio de las imágenes nos daría valiosos informes sobre la técnica de este baile de tensiones y contrastes que es Muerte sin fin. Ha. cen falta estudios de la sintaxis, y se está pidiendo a gritos la compara. ción con Mallarmé, pero no están dentro del propósito de nuestra tarea. Sin embargo, no sería fuera de lugar añadir en este momento un breve comentario sobre lo que ha logrado José Gorostiza. Cierto que es poeta de rango mayor: Murte sin fin es casi único, pesquisa coherente de la naturaleza fundamental de la realidad. La estructura del poema y su 
desarrollo son lógicos, pero la manera de desarrollarlo es altamente poética, iluminada por relámpagos de metáforas y múltiples niveles de comunicación. El resultado es una obra de proporciones heroicas.

Uno de los aspectos más interesantes de Muerte sin fin es su en. tronque con actitudes mexicanas. Ha aludido a esto Xavier Villaurrutia en su "Introducción a la poesía mexicana": "... el mexicano es un ser reducido, cuya embriaguez mayor consiste en mantenerse lúcido y que aún a la hora de soñar, gusta de mantenerse despierto". ${ }^{8}$ Dejando aparte el que esta lucidez de la cual habla sea acaso la nota más característica de su propia poesía, Villaurrutia ha enfocado bien una característica, si no de toda la poesía mexicana, ciertamente de algunos de sus mayores poetas. Sor Juana, a quien Gorostiza pidió prestada la imagen del agua y el vaso, se diferencia de los otros poetas barrocos por la lucidez, así como la mayoría de la generación de Villaurrutia y Gorostiza comparten esta característica, si bien de diversas maneras y hasta distinto punto. Acaso sea más importante aún la identificación de la obra de Gorostiza con actitudes populares mexicanas hacia la muerte. Ha subrayado esta identidad Ramón Xirau en su estudio "Poesía y pueblo". ${ }^{9}$ Señala acertadamente las semejanzas entre ciertos aspectos de la obra de Gorostiza -en especial la última parte-y el corrido, las calaveras, y otras manifestaciones populares. Ha creado Gorostiza esa obra inusitada, reflejo de la angustia del hombre culto y espejo de una actitud fundamental de su pueblo.

Frank Dauster

Universidad de Rutgers, New Burnswick, N. J.

7 Revista de la Universidad Micboacana, (Morelia), núm. 27, (abril-junio, 1951) p. 52.

8 Universidad de México, XII, núm. 2 (oct. 1957), pp. 1-3 y 8-10. 